\title{
Crato, Santo Antonio e o rio Madeira no contexto da economia da borracha
}

\section{Crato, Santo Antonio and the Madeira River in the context of the rubber economy}

Dante Ribeiro da Fonseca - Professor de História formado pela Universidade Federal do Rio de Janeiro (UFRJ) e exerce o magistério no Departamento de História da Fundação Universidade Federal de Rondônia -UNIR, na área de História da Amazônia. Doutor em Ciências: Desenvolvimento Sócioambiental pelo Núcleo de Altos Estudos Amazônicos (NAEA) da Universidade Federal do Pará (UFPA). EMAIL: zeliafonseca@brturbo.com.br

\section{Resumo}

O presente artigo trata da origem e desaparecimento de dois núcleos de povoamento no rio Madeira: São João Batista do Crato e Santo Antonio do Rio Madeira como fenômenos interligados em função da mudança das formas de exploração extrativa, do comércio e da navegação ao longo do século XIX. A ocupação colonial da Amazônia Ocidental, particularmente da Província da Amazonas, a partir da segunda metade daquele século, foi simultânea a uma série de processos históricos que resultaram no aumento do interesse boliviano no comércio por aquele rio, no adensamento da ocupação colonial no mesmo, especialmente em sua parte alta em razão da busca pela goma elástica e da navegação a vapor, que mudou a dinâmica do transporte. Tais fatores foram responsáveis pelo desaparecimento da povoação do Crato e pelo surgimento da povoação de Santo Antonio e seu posterior desaparecimento.

\section{Palavras-chave}

Crato, Santo Antonio, rio Madeira, borracha, Amazônia.

\begin{abstract}
This article deals with the origin and disappearance of two settlements on the Madeira River: São João Batista do Crato and Santo Antonio do Rio Madeira as interconnected phenomena due to the change in the forms of extractive exploitation, commerce and navigation throughout the century XIX. The colonial occupation of the Western Amazon, particularly from the Província do Amazonas, from the second half of that century, was simultaneous with a series of historical processes that resulted in an increase in Bolivian interest in trade in that river, in the thickening of colonial occupation in it, especially in its high part because of the search for rubber and steam navigation, which changed the dynamics of transport. These factors were responsible for the disappearance of the settlement of Crato and for the emergence of the settlement of Santo Antonio and its subsequent disappearance.
\end{abstract}

\section{Keywords}

Crato, Santo Antonio, Madeira river, rubber, Amazon. 


\section{INTRODUÇÃO}

Santo Antonio, no rio Madeira, hoje é mais conhecido pela usina hidrelétrica responsável pela extinção da cachoeira que ali existia. Na última metade do século XIX surgiu e floresceu naquele local um povoado, munido em certo tempo com grandes armazéns, bares, pensões, cartórios, juizado, intendência, destacamento de polícia, olaria, escola e outros equipamentos urbanos. Teve má fama durante a construção da Estrada de Ferro Madeira-Mamoré (1907-1912). Segundo Benigno Cortizo Bouzas (1950), espanhol que chegou a Santo Antonio em 1908, era uma próspera povoação. O médico sanitarista Osvaldo Cruz, definiu-a em 1909 como o pior espaço de todo o rio Madeira, sob o ponto de vista sanitário (CRUZ, 1972, p. 10). Socialmente a impressão era de que imperava o caos, conforme registrado por Bouzas e por Lobato Filho. Esse último, militar e membro da Comissão Rondon, afirmou em 1910 não existir em Santo Antonio os hábitos da velha família patriarcal, comuns às demais localidades daquele rio (1957, p. 28). Finda a construção da estrada de ferro a vila acomodou-se, aburguesou-se, por assim dizer e, por fim, desapareceu.

Esse desaparecimento não é um acidente exótico, faz parte da lógica do processo de transformações pelas quais passou a Amazônia entre a segunda metade do século XIX e as primeiras décadas do século seguinte. Nesse processo, a mudança na tecnologia dos transportes interferiu diretamente na dinâmica e funcionalidade das povoações, definindo uma relação causal entre a origem de umas e o desaparecimento de outras. Esse é o caso da relação entre Santo Antonio e São João do Crato, e depois da relação entre Santo Antonio e Porto Velho. O objetivo desse estudo é investigar essa dinâmica e seus efeitos sobre as duas povoações primeiramente nominadas ${ }^{1}$.

As primeiras tentativas de ocupação colonial de origem européia do rio Madeira iniciam já na segunda metade do século XVII, com o estabelecimento de missões religiosas. No curso do século XVIII foi aquele rio objeto de investidas repressivas e escravizadoras contra sua população nativa e campo para a prática do extrativismo ambulante e sazonal por parte dos novos povoadores coloniais. Outros fatores também contribuíram para a intensificação da presença colonial portuguesa na região naquele século XVIII: a) a descoberta do ouro no rio Guaporé em 1734; b) a criação da capitania de Mato Grosso e Cuiabá em 1748; c) o Tratado de Madri em 1750; d) a transformação em 1751 do rio Madeira em via

Sobre essa mesma dinâmica relacionada aos povoados de Porto Velho e Santo Antonio vide Fonseca, 2014, Capítulo I: Uma cidade à far West: tradição e modernidade na origem de Porto Velho.

Novos Cadernos NAEA • v. 20 n. $2 \cdot$ p. 73-90 • maio-ago 2017 
obrigatória para o comércio com o norte do Mato Grosso através de Belém; e) a fundação da capital da nova capitania chamada Vila Bela da Santíssima Trindade em 1752, no rio Guaporé.

Apesar dessas promissoras iniciativas a colonização daquele rio não se tornou efetiva, pois o configurou como uma mera rota de passagem entre Belém e Vila Bela. Assim é que através da Carta Régia de 12 de maio de 1798 a rainha de Portugal, D. Maria I, mandava D. Francisco de Souza Coutinho, governador e capitão-general do Estado do Grão-Pará, dar execução ao: “[...] bem concebido plano que [...] offereceis para a navegação d'essa Capitania por Matto Grosso [...]" (RIHGB, no. 14, 1842, p. 232). O principal objetivo do plano seria dar apoio aos viajantes, quando desfalcadas as expedições, fornecendo mantimentos e índios para o serviço de remo e carregamento (RIHGB, no. 14, 1842, p. 233).

Para essa finalidade foi fundada a localidade do Crato na foz do rio Jamari em 1798 com população composta por nativos do rio Negro e condenados pela justiça em Portugal ${ }^{2}$ (BAENA, 2004, p. 331). Em 1802 a povoação mudou de local e se fixou na margem esquerda do rio Madeira, abaixo da boca do rio Jamari, entre a praia do Tamanduá e o lago Cuniã (ABREU, 1896, p. 128). Em 1817 opinava Casal que muitas circunstâncias concorriam para tornar aquela vila uma das principais do rio Madeira, que equivocadamente chama Solimões (CASAL, 1817, p. 317), e de fato assim o foi por mais algumas décadas. Em 1828 ocorreu nova transferência da povoação. Depois de concedida a autorização do capitãogeneral do Pará ficou localizada entre os rios Baetas e Arraias, próxima ao ribeirão Maguarani e o igarapé Purus (ABREU, 1896, p. 128).

No final dos anos de 1850 Crato e Borba, antiga missão religiosa, eram as povoações de referência do Madeira. Mas eram povoações pequenas, medíocres, onde a atividade principal consistia na coleta de produtos florestais como cacau, salsaparrilha e cravo. Exploravam também a riqueza fluvial, principalmente através da pesca e salga do pirarucu. $\mathrm{Na}$ época do ano em que as tartarugas grandes iam desovar na praia do Tamanduá os moradores, e outros que vinham de fora com essa finalidade, coletavam seus ovos, com os quais produziam a manteiga de tartaruga, e capturavam os animais, produzindo com suas carnes as mixiras. Plantavam gêneros de primeira necessidade e algum tabaco. Desenvolviam alguma atividade de pastoreio. Possuía o Crato uma pequena igreja dedicada a São João Batista. Durante parte da segunda metade do século XIX a povoação se manteve como ponto de apoio à precária navegação que se fazia de Belém ou Manaus até Vila Bela da Santíssima Trindade, passando por Exaltación (Bolívia, baixo rio Mamoré) e outras localidades bolivianas.

Vide Mapa 2, ao final do texto. 
São João Batista do Crato e Santo Antonio do Rio Madeira representam épocas diversas do extrativismo naquele rio. A mais antiga, a época das ubás, do extrativismo sazonal e ambulante, pesqueiro e das drogas do sertão. A outra do avanço do extrativismo sedentário do sítio e do seringal, unidade rural especializada no extrativismo da borracha, uma inovação do século XIX que existiu enquanto durou o surto gumífero.

Santo Antonio do Rio Madeira aparece no contexto do surgimento e da expansão da navegação a vapor, então diretamente vinculado à expansão da produção extrativa, particularmente da borracha. Até o ano de 1866 manteve-se o Crato como porto final das linhas de navegação a vapor propostas pelo governo para o rio Madeira. Até os anos de 1870 não havia em Santo Antonio povoação que desse suporte à navegação. Aparentemente, a inexistência de povoação ao pé da cachoeira está vinculada à questão das fronteiras. O Tratado de Madri e depois o Tratado de Santo Ildefonso (1777) determinavam que desde a embocadura do rio Madeira até seu ponto médio, ambas as margens pertenciam ao Brasil. Do ponto médio até sua nascente, a margem direita estava em território brasileiro e a margem esquerda em território boliviano. Ocorre, contudo que as contestações sobre essa fronteira continuaram sendo feitas por ambas as potências coloniais e depois pelos países independentes. Em parte, a questão se resolveu em 1867 através do Tratado de Ayacucho. Nele, a Bolívia cedeu ao Brasil todo esse território, passando o rio Madeira a correr em ambas as margens integralmente em território brasileiro (FONSECA, 2007, Capítulo II).

Mas, em 1797 a incerteza quanto aos limites fronteiriços era uma realidade, pois recomendava a Carta Régia de 12 de maio de 1798: “[...] muito que se evitem todas as contestações sobre as povoações que vão estabelecer-se nas cachoeiras [...] os quais devem ser conservados e cobertos pela linha divisória [..]". Dada a insegurança quanto às lindes recomendava "[...] darem principio a este estabelecimento com algum respeitável armamento, a pretexto de conter os Indios, a fim de que os Hespanhoes vos respeitem, [...]" (RIHGB, no. 14, 1842, p. 239). Ainda assim, em razão do plano de navegação, foi criado outro ponto de apoio pela capitania do Mato Grosso, já no setor encachoeirado. Chamou-se, São José de Ribeirão (ou do Montenegro), que não resistiu ao tempo. É possível então que a escolha do local onde se estabeleceu a povoação do Crato tenha sido determinada por sua condição fluvial intermédia para o socorro aos navegantes, ou talvez por uma suposta melhor salubridade.

Diversos viajantes e exploradores passaram pelo rio Madeira no século XIX e deixaram seu depoimento sobre o estado da colonização daquele rio pela sociedade nacional. Iniciamos pelo boliviano José Augustin Palácios que partiu 
do departamento do Beni no ano de 1846 e desceu o rio Madeira até o final do trecho entre as cachoeiras (PALACIOS, 1893, p. 17). O tenente Lardner Gibbon navegou o rio Madeira de sua nascente até sua foz no ano de 1852. Chegou a Santo Antonio no dia 2 de outubro (GIBBON, 1854, pp. 301 a 305). Quatro dias após a passagem pela cachoeira de Santo Antonio Gibbon chegou a povoação do Crato. Caracterizou-a como um entreposto mercantil utilizado pela população nativa local, comerciantes do Pará, do Mato Grosso e da Bolívia (GIBBON, 1854, pp. 306-307).

Em 1858 o rio Madeira já apresentava, no contexto da economia provincial, importância como produtor de mercadorias diversificadas de origem principalmente extrativa. Resulta dessa importância que naquele ano dois empresários paraenses promoveram a primeira expedição de navio a vapor que temos conhecimento naquele rio. Partindo de Belém vapor "Guajará" navegou pelo rio Madeira até o Crato trazendo, no retorno, produtos extrativos ali adquiridos ou fretados. Em 1 de junho de 1861, o engenheiro João Martins da Silva Coutinho partiu de Manaus no vapor "Pirajá" para uma visita de exploração ao rio Madeira. Tinha como objetivo estudar os melhores locais para a instalação de colônias (FONSECA, JEGO, 2016).

Os engenheiros austríacos Franz e Joseph Keller saíram do Rio de Janeiro no dia 15 de novembro de 1867, chegando dia 10 de dezembro em Manaus a bordo do vapor "Belém", da Cia. do Amazonas. Vinham ao rio Madeira ao imperial serviço, para investigar soluções que melhorassem o transporte no trecho encachoeirado. Prosseguiram de canoa no dia 30 de maio de 1868 para o rio Madeira. Chegaram no dia 5 de julho ao Crato, que Keller observou simplesmente como uma estância para a criação de gado, onde estava situado o destacamento militar, que havia descido para aquela localidade em razão da insalubridade de Santo Antônio. Esse destacamento fora criado em 1867 (CLIB, 1867, p. 341, vol. 1, pt. II), mas ficou pouco tempo em Santo Antonio, em julho do ano seguinte já havia descido para o Crato (KELLER, 1869, pp. 4 a 22). O frade Jesualdo Maccheti, viajou da Bolívia até o Atlântico em 1869, passando pelos rios Madeira e Amazonas. Como todos os demais viajantes citados, não registrou a existência de povoação colonial em Santo Antonio ou no trecho encachoeirado (MACCHETI, 1869).

Em 1866, a presidência da província do Amazonas foi autorizada contratar uma companhia de navegação a vapor para atender as linhas dos rios Madeira, Purus e Negro (MATTOS, 1869, p. 51). Naquela década o Crato mantinha sua importância. Estava no ano de 1862 entre as três localidades de destaque no rio Madeira. Essas localidades estavam situadas às seguintes distâncias de sua foz: 
Borba, 25 léguas; Canumã, 47 léguas; Crato, 130 léguas. A cachoeira de Santo Antônio ficava a 168 léguas da foz do rio Madeira³ ${ }^{3}$ ou seja, a 38 léguas acima do Crato (MELLO, 1866, p. 341). Tavares Bastos registra em 1866 o distrito do Crato como possuidor do maior número de habitantes entre os distritos do rio Madeira, a saber: Borba, 2.335; Canumã, 529 e Crato 5.998 (BASTOS, 1866, p. 256). Em 1869 havia na província do Amazonas 212 casas comerciais e no rio Madeira: seis casas comerciais em Borba e treze no Crato (MATTOS, 1870, p. 35). Nos anos de 1870 era ainda o Crato uma povoação importante, pois no mês de março a Companhia Fluvial de Navegação do Alto Amazonas havia inaugurado sua linha para o rio Madeira com as seguintes escalas: Manaus, Canumã, Borba, Tabocal, Manicoré, Baetas, Juma, Crato, Cavalcanti, Santo Antonio (MATTOS, 1870, 38).

Em 1872 partiu da Inglaterra para Santo Antonio Edward Mathews, engenheiro encarregado de fiscalizar os trabalhos da Public Works Construction Co., empreiteira inglesa contratada para a primeira tentativa de construção da Madeira \& Mamoré Railway. A caminho de Santo Antonio, pouca palavra dedica Mathews ao Crato. Basicamente que se situa em um dos pontos mais desimpedidos do rio e que é lugar de pastagens (MATHEWS, 1879, p. 19). Quanto a Santo Antonio, também Mathews não menciona qualquer povoação ali existente antes da sua chegada. Registra apenas a presença de um contingente militar de aproximadamente 30 soldados comandados por um capitão (MATHEWS, 1879, p. 24).

Em 1874 subiu o rio Madeira a comissão instituída pela Amazon Steam Navigation Co. Ltd. para investigar os rios da bacia do Amazonas. Chegou ao Crato, uma povoação qualificada como "decente", situada em terreno alto à beira do rio Madeira com aproximadamente vinte casas e uma igreja. Encontraram dificuldades em satisfazer suas necessidades de abastecimento no Crato. Foram satisfeitas em Humaitá, cujos primórdios datam de 1869, onde observaram: “[...] uma verdadeira terra de abundância.” (BROWN; LIDSTONE, 1878, pp. 337-338)

Quando chegaram a Santo Antonio, os expedicionários definiram como: “[...] um aglomerado confuso de casas e galpões, flanqueado por algumas colinas baixas e ladeado pela cachoeira do rio Madeira à direita." (BROWN; LIDSTONE, 1878, p. 341). Seus habitantes? Mencionaram um francês de má aparência, o capataz da ferrovia e os militares da guarnição (BROWN; LIDSTONE, 1878, pp. 156, 341-342). Embora os expedicionários não mencionem explicitamente a composição e as características de outros moradores do povoado, sua existência

Observamos inconsistências quanto a esses dados, se consultados outros autores, contudo, como a precisão aqui não é imprescindível, na medida em que há a necessidade apenas de se ter uma ideia dessas distâncias, utilizaremos as informações acima.

Novos Cadernos NAEA • v. 20 n. $2 \cdot$ p. 73-90 • maio-ago 2017 
pode ser percebida através de pequenos fragmentos da descrição dos eventos ali ocorridos durante sua estada (BROWN; LIDSTONE, 1878, p. 347).

Quando a P. \& T. Collins chegou a Santo Antonio em 1878, para a segunda tentativa de construção da ferrovia, havia uma habitação e depósito de um comerciante local, térrea e de estilo rústico feita de "lascas de palmeira" e outra parecida, que estava ocupada pelo comandante do destacamento militar. Também as edificações construídas pela Public Works, todas desocupadas e arruinadas. No mesmo ano, João Severiano da Fonseca também passou por aquela vila que, segundo seu testemunho, compunha-se de algumas casas cobertas de zinco e palha e apenas um sobrado e um barracão abandonado pela ferrovia (na verdade eram dois), além de um destacamento com quinze praças do $3^{\circ}$. Batalhão de Artilharia e uma subdelegacia de polícia (FONSECA, vol. 2, 1881, p. 309).

Assim, entre os anos de 1872 e 1878 iniciou a surgir a povoação na base da cachoeira de Santo Antonio do Rio Madeira. O que agregou população naquele local? Antes da chegada da linha de navegação a vapor (1870) no rio Madeira, a parada na cachoeira para continuar a viagem não estimulava a fixação de população no local. Os trabalhos de carga, descarga e varação eram feitos pelas próprias tripulações que remavam as canoas. Além disso, não terminavam ali sua viagem, mas prosseguiam até o rio Amazonas. Assim, a povoação do Crato, para a qual se dirigiam as canoas, desempenhava o papel de suporte ao tipo de navegação praticado antes do vapor.

A chegada da navegação a vapor na região poderia ser o elemento que viria estimular a fixação de população no local? Quando a Public Works desembarcou seus funcionários em Porto Velho, em 1872 fazia coisa de dezoito meses que a linha regular de navegação entre Manaus e Santo Antonio do Rio Madeira havia sido inaugurada. O fato de a linha prover paradas no Crato é indicativo da manutenção de sua condição como importante porto do Madeira. Durante alguns meses após a inauguração da navegação a vapor as canoas continuaram a ter como ponto de referência o Crato. Mas com o vapor no rio Madeira a carga não seguia mais a remo para o Porto de Itacoatiara (AM), de onde continuava até o seu destino pelos vapores da Cia. do Amazonas. Desde 1870 a função do Crato mudou: de porto de apoio para a continuidade da viagem das embarcações a remos para entreposto onde eram transladadas as mercadorias dos vapores para as canoas ou vice-versa. Vale salientar que além das chegadas regulares dos navios de linha, recebia também aquele porto, assim como Santo Antonio, outros navios de comerciantes e empresas aviadoras.

A linha a vapor não isentou os produtores de continuarem com o mesmo tipo de transporte que já vinham realizando no trecho encachoeirado. Pouco 
a pouco, dada a maior comodidade, essas mercadorias passaram a estacionar em Santo Antonio, a espera dos vapores. Essa escolha permitia economizar aproximadamente quarenta léguas de navegação a remo entre o Crato e aquele ponto, que Gibbon gastou quatro dias para navegar. Ficavam as tripulações aguardando os vapores. Uma população, sazonal, passou a compor a nascente povoação. Em Santo Antonio era necessário descarregar os navios, depois transportar as mercadorias do porto dos vapores ao porto das canoas, acima da cachoeira, e finalmente fazer a navegação entre as cachoeiras. Com o tempo, foram construídos galpões e depósitos, para guarda das mercadorias que esperavam os vapores ou pelas ubás. Também houve a necessidade de um comércio de gêneros para abastecer as tripulações dessas canoas, pelo menos enquanto aguardavam os aviamentos que chegariam pelos vapores.

Figura 01 - Cachoeira de Santo Antonio: Ponto A: Porto das Canoas. Ponto B: Porto dos Vapores

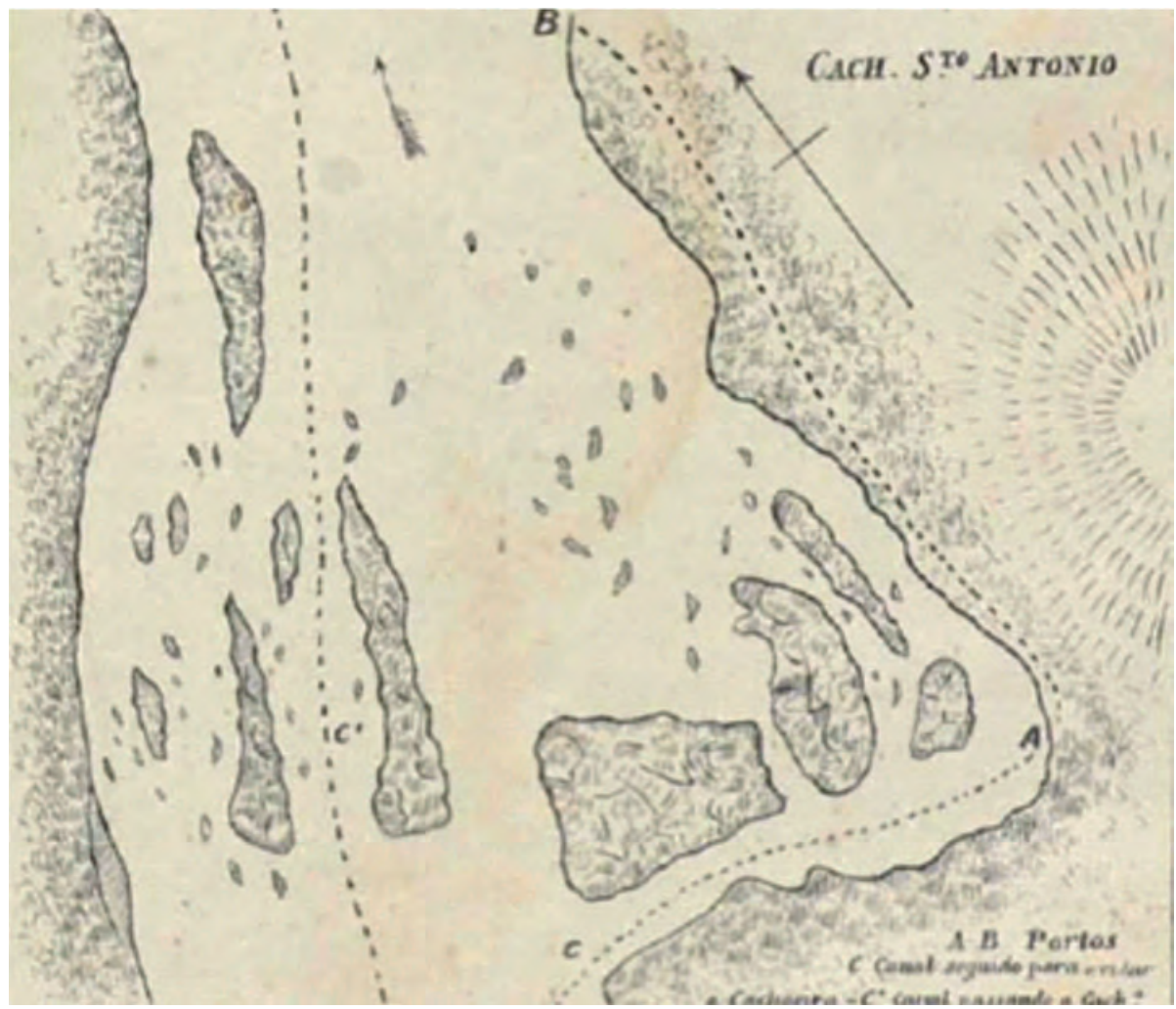

Fonte: FONSECA, 1881, p. 309. 
$\mathrm{Na}$ década de 1880 um viajante traçou um quadro bastante desanimador da povoação, embora as informações seguintes permitam-nos vislumbrar uma pequena população fixa. O viajante ficou hospedado na casa de um comerciante, que possuía residência, casa comercial e armazéns. Certamente essa casa comercial possuía empregados que residiam no povoado. Registra também a presença de um subdelegado de polícia e soldados da guarnição, em número de três ou quatro. Observou no local as canoas dos seringalistas que se deslocaram a Santo Antonio para receber os aviamentos enviados das firmas do Pará ou Manaus destinados ao inicio do fábrico ou para embarcar àqueles aviadores as pélas de borracha que produziram. Enquanto os nativos ficavam aguardando a chegada dos vapores para receber ou despachar as mercadorias executavam diversos trabalhos, como reparar as avarias causadas nas canoas pela difícil navegação nas cachoeiras, preparando-as para o retorno (SILVA, 1891, pp. 179-196).

$\mathrm{Na}$ mesma década visitou a povoação Ernesto Matoso Maia Fortes, que a serviço do governo imperial era componente da comissão Morsing/Pinkas, destinada a promover estudos de viabilidade da ferrovia no trecho das cachoeiras. Deslocando-se no vapor da Cia. do Amazonas em companhia de seringalistas bolivianos depararam-se, ao chegar a Santo Antonio, com 300 nativos bolivianos que aguardavam esses patrões. Carregariam as canoas com a mercadoria trazida por esses patrões e seguiriam rio acima para os estabelecimentos rurais onde trabalhavam (FORTE, 1883, p. 84).

Com a consolidação do transporte a vapor e o surgimento de outras localidades no rio Madeira, como Humaitá, Manicoré e Santo Antonio, aliado ao crescimento da colonização a montante, o Crato foi decaindo como ponto de apoio à navegação no alto rio Madeira, transferindo essa condição para Santo Antonio. A perda de importância dessa localidade é visível na literatura, o barão de Marajó registrou em 1896 que os dois centros de população mais importantes no rio Madeira eram Borba e Manicoré (ABREU, 1896, p. 127). Em 1909 a sexta linha da Amazon Steam, de Belém a Santo Antonio, não mais fazia escala no Crato (CIB, v. III, 1909, p. 100).

Em 1907 iniciou a última tentativa de construção da ferrovia MadeiraMamoré, criando a perspectiva de maior dinamismo comercial na região em razão da obra. Por essa razão, no relatório de 1911 o governador do Mato Grosso ressaltou a importância da resolução do problema de limites com o Amazonas no rio Madeira, que se arrastava desde 1891. A urgência da iniciativa relacionava-se 
diretamente com as receitas fiscais do Mato Grosso recolhidas pela Delegacia do Norte, que tendiam a aumentar com a conclusão das obras da ferrovia MadeiraMamoré. Situar o porto de Santo Antonio dentro do território do Mato Grosso era condição fundamental para o gozo dessas vantagens. Então o governo do Mato Grosso reafirmou sua jurisdição ao criar a comarca e o município de S. Antonio do Madeira em 1908 (COSTA, 1911, pp. 8-9).

A população da área da povoação havia crescido bastante. Um levantamento aproximado totalizou 1.800 habitantes em 1912 (O Debate de 31/05/1912). Outra estimativa aponta que em 1909 a povoação possuiria uma população estimada de 2.000 habitantes a qual era acrescida mais 3000 pessoas por ocasião da chegada da borracha para ser embarcada. Algum comércio, como o comércio a retalho, havia se desenvolvido no local. De modo que Osvaldo Cruz informa que quando os batelões retornavam aos seringais conduzindo mantimentos a povoação ficava desabastecida (CRUZ, 1909, p. 10). Em 1911 o governo do Mato Grosso elevou a povoação à categoria de vila (MENEZES, 1988, p. 192). No ano de 1912 acreditava aquele governo que: "A velha questão de limites com o Estado do Amazonas está hoje felizmente dependendo apenas de homologação do Supremo Tribunal Federal para sua solução definitiva." (MARQUES, 1912, p. 9). O Município foi instalado em dois de julho de 1912. No mesmo ato tomou posse como seu prefeito o médico Joaquim Augusto Tanajura.

Com a finalização da construção da Madeira-Mamoré novas povoações surgiram no seu leito, inclusive Porto Velho, no seu ponto inicial. Em razão do surgimento de Porto Velho, o futuro de Santo Antonio já era objeto de dúvidas naqueles anos nos quais, paradoxalmente, esse povoado crescia e encontrava seu apogeu. Em 1910 o Dr. João de Moraes e Mattos foi enviado de Cuiabá à Santo Antonio para tratar da questão da fronteira com o Amazonas (O Commercio de 15/09/1910). Em entrevista concedida ao jornal "O Debate” de Cuiabá, no ano seguinte, o referido juiz declara emblematicamente que: "Em Porto Velho o sr. olha para o futuro [...] e em Santo Antonio o sr. recorda-se do passado [...] (O Debate de 04/09/1911). È necessário notar que quando o entrevistado fala em Porto Velho, na verdade está se referindo ao pátio ferroviário, cuja moradia era exclusivamente usufruída pelos norte-americanos. Assim, todos os benefícios e confortos que são elencados na literatura pertinente eram propriedade particular da ferrovia. De fato, a povoação que se estava formando na fronteira desse pátio mal começara e sua feição social e sanitária era mais próxima à de Santo Antonio 
(FONSECA, Capítulo IV, 2007, pp. 86-142). Talvez por isso foi essa área ignorada por grande parte dos viajantes naquele momento. Preferiam observar a luz feérica da modernidade gerada no pátio ferroviário que o arcaísmo revelado no nascente aglomerado que o circundava.

Santo Antonio aparentava progredir, apesar das dúvidas em relação ao seu futuro. Em 1917 um soldado que lá servira testemunhou a um jornal de Cuiabá suas impressões sobre a vila. Contrariamente aqueles testemunhos do período da construção da ferrovia Madeira-Mamoré, que apresentava a vila como um local de desordem, a povoação era qualificada como pacata. Formada por gente laboriosa, onde, apesar da atração de trabalhadores que exercia Porto Velho, já se via alguma atividade agrícola que lhe pudesse garantir um bom futuro (O MattoGrosso de 9/06/1918).

Alguns aspectos, porém, indicavam já as causas de sua decadência futura. Primeiramente a queda no preço da goma elástica no mercado internacional, que coincide com o término da construção da ferrovia. Em segundo lugar, instituídos os limites que colocavam a vila dentro do Mato Grosso, deixa o Amazonas de se interessar pelos seus problemas. Ademais, o surgimento de Porto Velho dentro do município amazonense de Humaitá faz com que aquele estado dirija seus esforços para o desenvolvimento daquela povoação. Finalmente, a vizinhança do pátio ferroviário torna Porto Velho mais atraente, pois com o tempo compartilhará, em parte, os benefícios e confortos criados pela ferrovia. Contrariamente às previsões otimistas dos administradores públicos do Mato Grosso, a conclusão da comissão federal de fiscalização dos trabalhos da Madeira-Mamoré em 1912 é outra: "Porto Velho, com todos seus recursos servirá de refúgio aos trabalhadores e seringueiros da nova região, que se abre ao commércio. (DOU, 07/02/1912, p. 1789). Em 1914, foi criado o município de Porto Velho, e instalado no ano seguinte.

Por essas razões, vila de Santo Antonio foi se esvaziando nas décadas seguintes. De tal modo que a população urbana dos três municípios que compuseram o Território do Guaporé estava assim distribuída em 1 de setembro de 1940: Porto Velho, 2.341, Guajará-Mirim, 1743, e Alto Madeira (Santo Antonio), 58, totalizando 4.142 pessoas. Essa população urbana abrigava-se em uma povoação que possuía naquele ano de 1940 um domicílio de alvenaria e dezessete domicílios de madeira (IBGE 1952, p. 138).

O município de Santo Antonio do Rio Madeira, chamado então de Alto 
Madeira, ainda existia em 1943, quando foi criado o Território Federal do Guaporé (Decreto-Lei 5.812 de 13/09/1943. In: GER, 1990, pp. 66-67)루, atual Rondônia. Após a criação do Território mudanças foram realizadas na composição dos seus municípios que culminaram com uma nova divisão administrativa em 1945. Fixou essa divisão a existência de apenas dois municípios no Território Federal do Guaporé: Porto Velho, que absorveu a área do município do Alto Madeira, e Guajará-mirim. (Decreto-Lei 7.470 de 17/04/1945. In: GER, 1990, pp. 109-113).

Algumas décadas antes, em fevereiro de 1909, aportou em Porto Velho o jornalista inglês Henry Major Tomlinson. Permaneceu visitando essa localidade e Santo Antonio entre 16 de fevereiro e 10 de março, tempo necessário para escrever suas observações. Concluiu sobre Santo Antonio o seguinte: "O que o homem tinha construído parecia insignificante e transitório, ao lado dos contornos refinados das pedras [...]" apesar disso, declarou saber que: "[... quando os dias do barracão da borracha tivessem passado, meu povoado ainda estaria lá e prosperando.” (TOMLINSON, 2014, pp. 281-282). Teve o viajante a impressão incorreta, pois toda obra humana não apenas parece, mas é, ao final, insignificante e transitória. Não podia imaginar o quanto estava errado quanto à permanência $\mathrm{e}$ prosperidade da vila. Por outro lado, não percebeu também o quanto o homem pode tornar passageiras mesmo as obras da natureza. Não somente o povoado, mas aquelas pedras da cachoeira, tão graníticas e monumentais, aparentando a solidez da eternidade, foram também pulverizadas. Como o amor do poeta se revelaram afinal eternas, apenas enquanto duraram. Insignificantes e transitórias, pois “tudo o que é sólido desmancha no ar". Décadas depois quase não havia mais vestígios daquele povoado, um pouco mais e desapareceram também os colossos, transformaram-se em barragem. Requiescat in pace.

$4 \quad$ Vide mapa 1 ao final do texto.

Novos Cadernos NAEA • v. 20 n. $2 \cdot$ p. 73-90 • maio-ago 2017 
Mapa 1 - Território Federal do Guaporé de 1943, com os municípios de Alto Madeira e Lábrea.

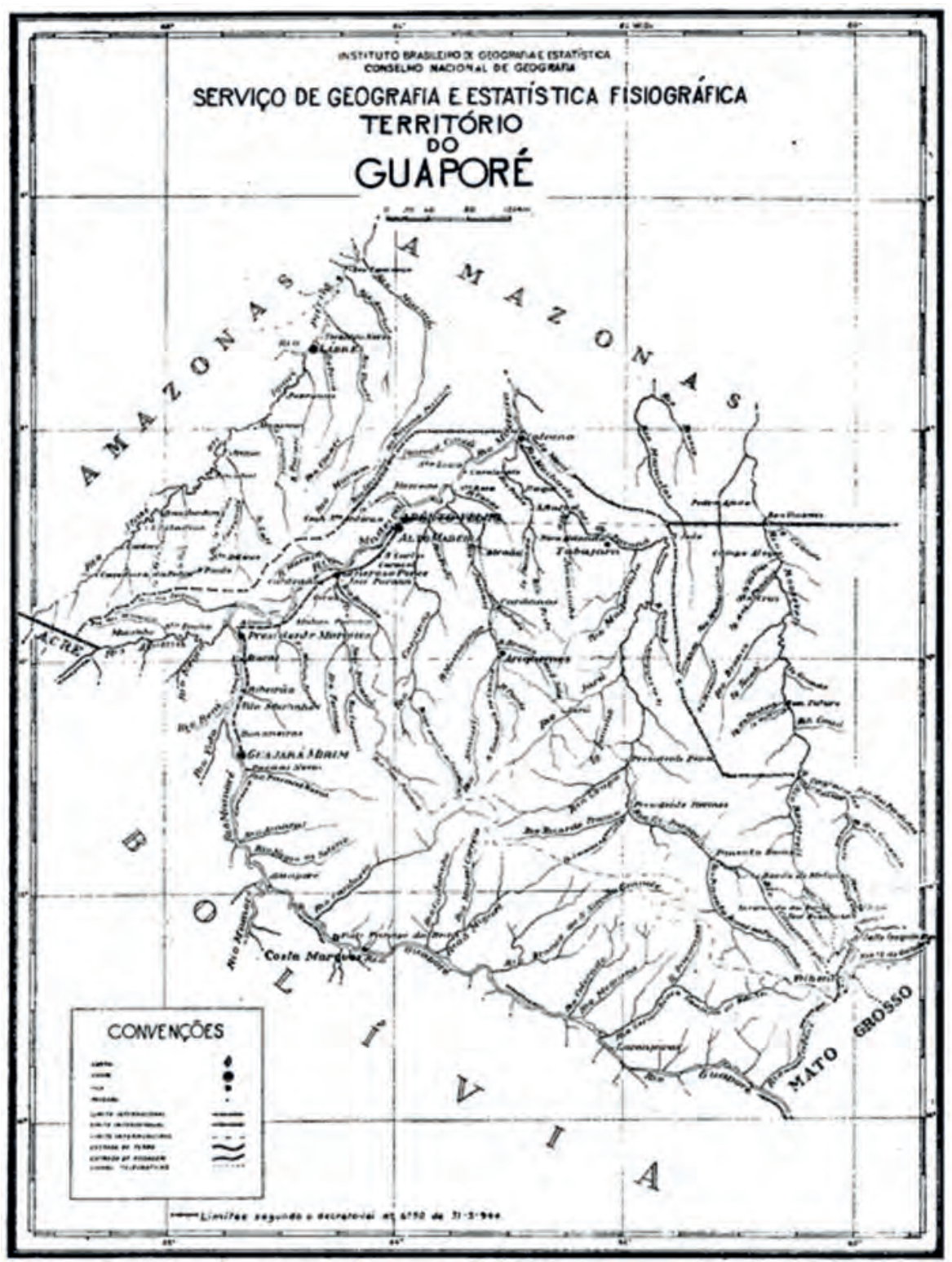

Fonte: GUIMARÃES, 1944, p. 853. 
Mapa 2 - O Território Federal do Guaporé após as modificações de 1945

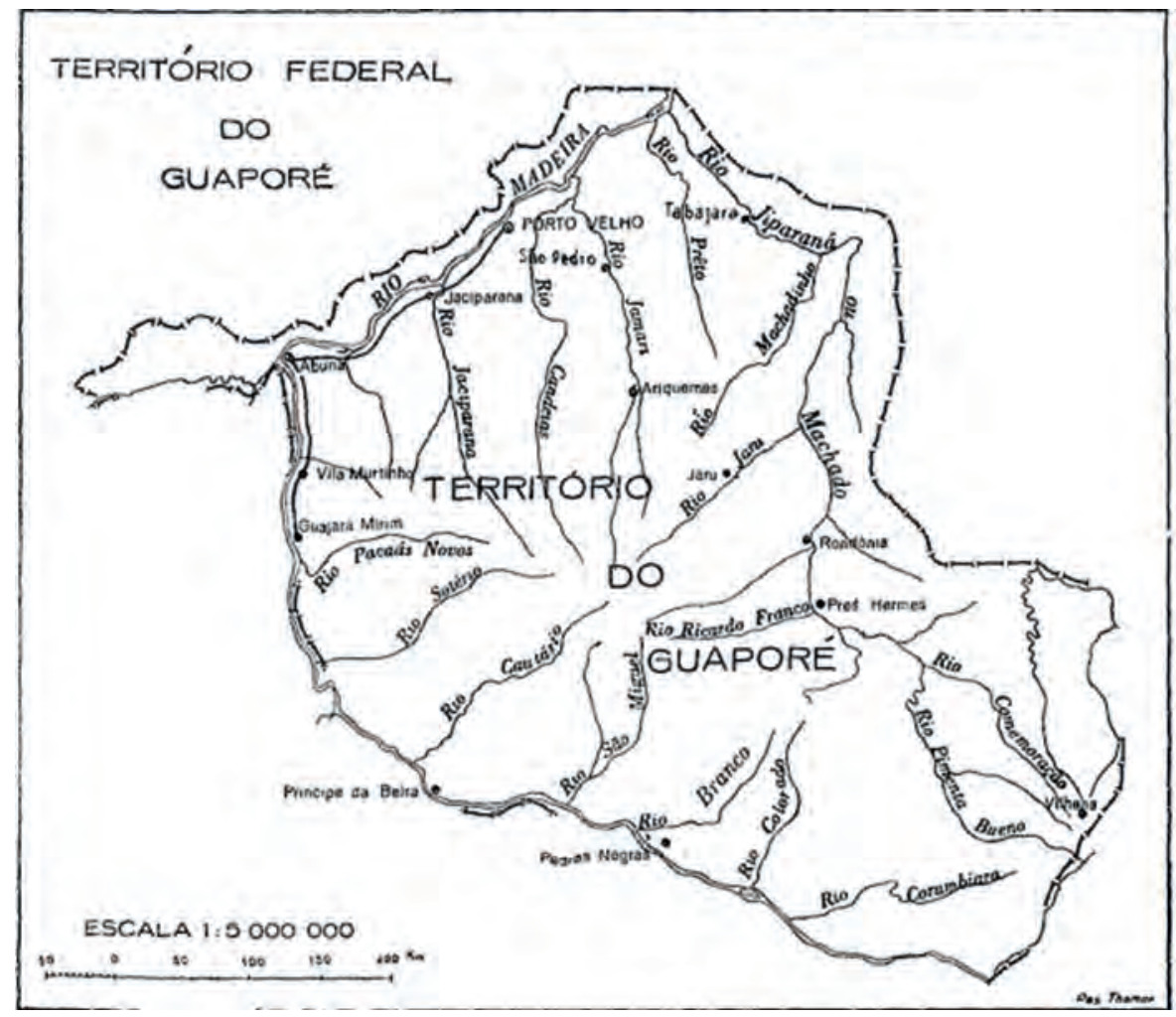

Fonte: GUERRA, 1953, 184.

\section{REFERÊNCIAS}

ABREU, J. C. da G. e (barão de Marajó). As regiões amazonicas: estudos chorographicos dos estados do Gram Pará e Amazonas. Lisboa: Imprensa de Libanio da Silva, 1896.

Acta da installação do município de Santo Antonio do Rio Madeira. Acervo do Arquivo Público de Mato Grosso.

BAENA, A. L. M. Ensaio corográfico sobre a província do Pará. Edições do Senado Federal, v. 30. Brasília: Senado Federal, Conselho Editorial, 2004.

BASTOS, A. C. T. O valle do Amazonas: estudo sobre a livre navegação do Amazonas. estatistica, producções, commercio, questões fiscaes do valle do Amazonas. Rio de Janerio: B. L. Garnier, 1866. 
BOUZAS, B. C. Del Amazonas al infinito. Recife: Diário da Manhã, 1950.

BROWN, C. B.; LIDSTONE, W. Fifteen thousand miles on the Amazon and its tributaries. London: Edward Stanford, 1878.

CASAL, M. A. de (1754-1821). Corografia brazilica, ou relação historicogeografica do reino do Brazil: composta e dedicada a Sua Magestade fidelíssima. Caminha, Pero Vaz de, 15th cent. Carta; Brazil. Alvará (1817 Aug. 21). Rio de Janeiro: Impressão Régia, 1817.

CIB - CENTRO INDUSTRIAL DO BRASIL. O Brasil suas riquezas naturaes suas industrias. Volume III: Introducção, Industria de Transportes e Industria Fabril. Rio de Janeiro: M. Orosco e Cia. 1907. Edição fac-similar, IBGE, 1986.

CLIB - Collecção das Leis do Imperio do Brasil de 1867. Tomo XXX, parte II. Rio de Janeiro: Typographia Nacional, 1867.

COSTA, P. C. C. da. Mensagem dirigida pelo Coronel 1o. Vice-Presidente do Estado, em exercicio, Á Assembléa Legislativa ao installar-se a 3a. Sessão da 8a. Legislatura, em 13 de Maio de 1911. Cuyaba: Typographia Official, 1911.

CRAIG, N. B. Estrada de Ferro Madeira Mamoré: história trágica de uma expedição. São Paulo: Nacional, 1947.

CRUZ, O. G. Considerações gerais sobre as condições sanitárias do rio Madeira. Rio de Janeiro. Papelaria Americana, 1910. In: Sobre o saneamento da Amazônia. Manaus.,Philipe Daou, 1972.

DOU - Diário Oficial da União, 07 de fevereiro de 1912, pp. 1779- 1796. Ministério da Viação e Obras Públicas. Commissão Extraordinária de Fiscalização da Estrada de Ferro Madeira e Mamoré. Relatório dos trabalhos de fiscalização extraordinária da Estrada de Ferro Madeira e Mamoré. Apresentado pelos membros da commissão em 15 de dezembro de 1911: Álvaro Lessa e Manoel Joaquim Pereira Pinto Sayão ao Exm. Sr. Dr. José Joaquim Seabra D.D. Ministro de Estado da Viação e Obras Públicas.

EDWARDS, W. H. (William Henry), 1822-1909. A voyage up the river Amazon: including a residence at Para. Ithaca, New York: Cornell University Library Print source: New York: D. Appleton and Co, 1847.

FERREIRA, M. R. A ferrovia do diabo: história de uma estrada de ferro na Amazônia. São Paulo: Melhoramentos, 1959. 
FONSECA, D. R. da. A História e a cultura na fronteira rondoniense Brasil/ Bolívia. In: Estudos de História da Amazônia. Volume II, Capítulo I, pp. 1774. Porto Velho: Nova Rondoniana, 2016.

FONSECA, D. R. da. Fronteiras incertas: a colonização do rio Madeira. In: Estudos de História da Amazônia. Volume I, Capítulo II, pp. 25-51.Porto Velho: Maia, 2007.

FONSECA, D. R. da. O "Guajará" e o início da navegação a vapor no rio Madeira. Publicado em 24/12/2016. Jornal Eletrônico Gente de Opinião JEGO -. Porto Velho, Rondônia. Disponível em: < http://www.gentedeopiniao. com.br/imprimir.php?news=161015> Acessado em: 02/01/2017.

FONSECA, D. R. da. Uma cidade à far west: tradição e modernidade na origem de Porto Velho. In: Estudos de História da Amazônia. Capítulo IV, pp. 86142. Porto Velho: Maia, 2007.

FONSECA, J. S. da. Viagem ao Redor do Brasil (1875-1878). Volume 2. Rio de Janeiro: Typographia de Pinheiro \& C., 1881.

FORTE, E. M. M. Do Rio de Janeiro ao Amazonas e Alto Madeira: Itinerario e trabalhos. Comissão de Estudos da Estrada de Ferro do Madeira e Mamoré. Impressões de viagem por um dos membros da mesma comissão. Rio de Janeiro: Typographia a vapor de Soares \& Niemeyer, 1883.

GER - GOVERNO DO ESTADO DE RONDÔNIA. Coleção das leis de Rondônia: legislação referente aos territórios e à Amazônia. Porto Velho: GH/comunicação Gráfica, 1990.

GIBBON, L. Exploration of the valley of the Amazon, made under direction of the Navy department by Lewis Herndon and Lardner Gibbon,lientenants United States Navy. Vol. 2. by lieut. Lardner Gibbon. Washington: A. O. P. Nicholson, Public Printer, 1854.

GUERRA, A. T. Observações Geográficas sôbre o Território do Guaporé. Revista Brasileira de Geografia. Ano XV, no. 2, abril-junho de 1953.

GUIMARÃES, F. M. S. Contribuição ao ensino: Território Federal do Guaporé. Associação dos Geógrafos Brasileiros. Boletim Geográfico. Ano II, fevereiro de 1944, no. 18, p. 852.

IBGE - Serviço Nacional de Recenseamento. Série Regional. Parte XXII Mato Grosso - 1940. Serviço Gráfico do Instituto Brasileiro de Geografia e Estatística, 1952. Recenseamento Geral do Brasil. [1o. de Setembro de 1940] 
Série Regional. Parte XXII - Mato Grosso. Censo Demográfico. População e Habitação. Censos Econômicos Agrícola, Industrial, Comercial e dos Serviços. Brasil.

KELLER, F. Anexo X: Exploração do Rio Madeira na parte compreendida entre a cachoeira de Santo Antonio e a barra do Mamoré. In: Relatório da Repartição dos Negócios da Agricultura, Comércio e Obras Públicas. Rio de Janeiro: Typographia do Diario do Rio de Janeiro, 1869.

KELLER, F. The Amazon and Madeira river: sketches and descriptions from the note-book of an explorer. New edition with sixty-eight illustrations on wood. Philadelphia: J. B. Lippincott \& Co., 1875.

LOBATO FILHO (Gal.). Avançai para o Jamarí: a comissão Rondon nas selvas do alto Madeira. Rio de Janeiro: s/ed., 1957.

MACCHETI, J. Diario del viaje fluvial del padre fray Jesualdo Maccheti, misionero del Colegio de la Paz, desde San Buenaventura y Reyes hasta el Atlántico en 1869. La Paz: Imprenta de "El Siglo Industrial”, 1869.

MARQUES, J. A. da C. Mensagem dirigida pelo [...] [...] Á Assembléa Legislativa [...] 13 de Maio de 1912. Cuyaba: Typographia Official, 1912.

MATHEWS, E. D. Report to the directors Madeira and Mamore Railway Company, Limited, by Edward D. Mathews, resident engineer, upon his return from Brazil and Bolivia, 1875. London: Waterlow \& Sons, Printers, Great Winchester Street. 1875.

MATHEWS, E. D. Up the Amazon and Madeira Rivers through Bolivia and Peru. London: SampsonLow, Marston, Searle \& Rivington, 1879.

MATTOS, J. W. (Ten.-cel.) Relatorio lido pelo exm. osr. presidente da provincia do Amazonas, na sessão d'abertura da Assembléa Legislativa Provincial á 25 de março de 1870. Manaos: Typographia. do Amazonas, 1870.

MATTOS, J. W. (ten.-cel.). Relatorio com que o exm. osr. presidente da provincia do Amazonas abrio a Assembléa Legislativa Provincial no dia 4 de abril de 1869. Manáos: Typographia do Amazonas, 1869.

MELLO, A. E. de. Relatório com que o Exmo. Snr. Dr. Antonio Epaminondas de Mello entregou a administração da Provincia do Amazonas ao Exmo. Snr. Dr. Gustavo Adolpho Ramos Ferreira, vice-presidente da mesma. Recife: Typographia do Jornal do Recife, 1866. 
MENEZES, E. P. Retalhos para a história de Rondônia. 2. ed. revista e ampliada. Porto Velho: Gênese, 1988.

O Commercio, Cuiabá [Periódico], anno I, no. 29, 15 de setembro de 1910 Santo Antonio do Rio Madeira Limite com o Amazonas.

O Debate, Cuiabá [Periódico], anno I, no. 205, 31 de maio de 1912.

O Debate, Cuiabá [Periódico], anno I, no. 38, 04 de setembro de 1911.

O Matto-Grosso, Cuiabá [Periódico], anno XXIX, no. 1494, 9 de junho de 1918. Santo Antonio Batalhão de Infantaria e extorsões

PALACIOS, J. A. Exploraciones realizadas en los ríos Beni, Mamoré y Madera y el Lago Rojo-Aguado durante los años 1844 al 47: Descripción de la Provincia de Moxos. La Paz: El Comercio, 1893.

PINTO, E. P.. Hidrovia do Grão-Pará a Mato Grosso: projeto de integração da Amazônia colonial entre os rios Madeira, Mamoré e Guaporé (17971800). Porto Velho: ABG, 1998.

QUEVEDO, Q. E1 Madera y sus cabeceras. Cochabamba: Tipographia de Quevedo, 1861.

RIHGB - Cópia da Carta Régia de 12 de maio de 1798 sobre o plano de navegação para o Mato Grosso pelo rio Madeira. In: Revista do IHGB. Rio de Janeiro, no. 14, julho de 1842, pp. 232-239.

SILVA, B. da C. e. Viagens no sertão do Amazonas: do Pará à costa do mar Pacífico pelo Amazonas, Bolívia e Peru. Porto: s/ed., 1891.

TOMLINSON, H. M. O mar e a selva. Relato de um inglês na Amazônia. Tradutor Hélio Rodrigues da Rocha Jundiaí: Paco Editorial, 2014. 